\title{
DEVELOPING SUSTAINABLE PLANNING FOR HERITAGE CONSERVATION IN THE TROPICS: A GIS-BASED RISK AND VULNERABILITY ASSESSMENT PROFILE FOR HISTORIC ARCHIVES IN PUERTO RICO
}

\author{
JOHNNY LUGO VEGA ${ }^{1} \&$ DANIEL DÍAZ ${ }^{2}$ \\ ${ }^{1}$ University of Puerto Rico, Río Piedras, Puerto Rico \\ ${ }^{2}$ Puerto Rico Board of Planning, Puerto Rico
}

\begin{abstract}
Puerto Rico was declared a disaster area by the United States Government, after the pass of Hurricane María on September 2017. The University of Puerto Rico in Río Piedras, Puerto Rico (UPR RP), Archired a non-profit organization and the Puerto Rico Planning Board have proposed to develop a risk assessment model for a disaster planning, response, recovery and mitigation GIS based plan. The stewardship of archives, art and Puerto Rican cultural heritage collections was very vulnerable to natural events such as hurricanes and flood in mostly all Puerto Rico's Island. This study was brought in order to show the feasible steps to develop this important tool as part of an integrated effort in developing sustainable planning. The study consisted in the relations of some natural events in the tropics, and the cultural heritage collections at five (6) archives with different locations and buildings type. Base data was collected using an electronic in-house "app" questionnaire with key questions related to the attributes of the collection, the building and the surrounding biophysical characteristics. We design a space-location mapping of each location using a Geographic Information System, in collaboration with the Puerto Rico's Planning Board interactive Map resources. The results showed a highest correlation for urban flood and earthquake risk and vulnerability estimation while volcanism and Sahara dust represents the contrary, by now. This tool represents a necessary planning tool for the development of a master sustainable conservation planning project in Puerto Rico.
\end{abstract}

Keywords: Puerto Rico, historic archives, risk assessment, GIS, sustainable heritage conservation, survey.

\section{INTRODUCTION}

In Western society, risk and vulnerability are words that are associated or suggest estimating the relationship of adaptation and resilience in natural ecosystems [1], [2]. However, in the human environment relationship, it implies an exercise of interpretation of our form of social organization within the immediate, regional or planetary space, together with all the structures and technologies developed by the human being. That is, the population and the built artifacts also suggest that, once an event occurs, such occurrence is accompanied by the probability of a loss. To begin with the intention of creating a knowledge about these events as risk and their effects in a tropical climate in Puerto Rico, we can give a closer look at the amount of definitions in the literature, especially the concept of risk [3]. Between, February 2016 and January 2017, a basic guide was distributed, as a first questionnaire (now on, Q1) to estimate, in a preliminary way, the risk and vulnerability relationship for archival materials in Puerto Rico. Seven (7) archives belonging to the Puerto Rico Archives network, called ArchiRed was selected. Each one has a different location, in geographical terms, including four (4) of them, located nearby the San Juan metropolitan area. We started with a simple workshop hands-on experience for the description and identification of natural risks for each archive in Puerto Rico. 


\section{THE BIOPHYSICAL CHARACTERISTICS OF PUERTO RICO AS POTENTIAL RISKS}

The main island of Puerto Rico is located between about $17^{\circ} 45^{\prime} \mathrm{N}$ and $18^{\circ} 30^{\prime} \mathrm{N}$, and $65^{\circ} 45^{\prime}$ $\mathrm{W}$ to $67^{\circ} 15^{\prime}$. This geographical position places Puerto Rico in the Antillean Geologic formation. The tectonic plate of the Caribbean, where Puerto Rico resides, is a fragment of the Pacific plate that has been moving to the northeast, between the north and South American plates for more than 100 million years. This process caused the collision of the Atlantic tectonic plate by creating an arc of volcanic islands that included Puerto Rico. For this reason, the island is divided geologically into three igneous provinces; the Northwest, center and southwest, based on the age and composition of the rocks present. As shown in Fig. 1, the geological diversity of the Puerto Rico came from the Antillean Arch, created various sedimentary materials that are conjugated in the Puerto Rican archipelago. In addiction the geological process of Puerto Rico gave way to different geologic materials, whose nature or composition have defined their stability and historically influenced the patterns of settlement of Puerto Rican societies since the Holocene to the present [4].

\subsection{Geology, Bathymetry, Earthquakes and Tsunamis}

In this way we can talk about the geological reality and infer about the tectonic reality of Puerto Rico with respect to the geomorphology of the Caribbean. The microplates that make up the Puerto Rican archipelago are influenced by the Caribbean plate and this in turn, by the tectonic margins of the plates of North America and that of the Caribbean, whose movements or activity define the potential of tectonic risk in the Area. A recent study by the National Administration for the atmosphere and Oceans (NOAA) created a map of the elevation profile and depth of the surface in three dimensions of the Caribbean Sea. Known as bathymetric map, this map reflects with details, underwater geomorphology and the fossa of Puerto Rico, which responds to one of those specific characteristics of our geoseismic activity.

\subsection{Floods, droughts and landslides}

In general terms, the atmospheric characteristics of Puerto Rico are typical of the tropical in the Caribbean basin. Now, what scientific elements might explain what people call "tropical". The influential patterns producing our biophysical characteristics are related most to the Atlantic Ocean rather than the Caribbean Sea.

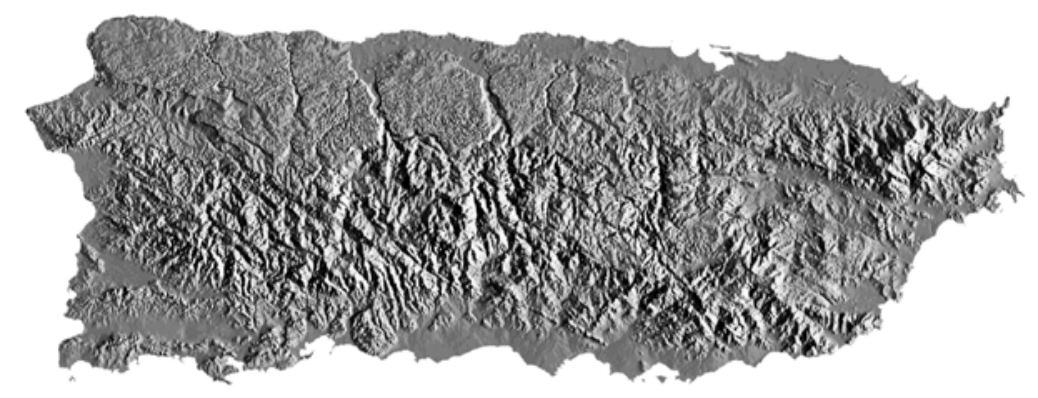

Figure 1: Monochromatic topographical map of Puerto Rico's main island. 
The risks of the macro-climatic scale are related to global dynamics such as the global atmospheric circulation of air, the belt currents of the Atlantic Ocean and the oscillations of the sea surface temperature are now indicators of climate Change [5]. All of them have a direct influence on the climate patterns of the Caribbean and Puerto Rico. In that way, floods and landslides are also induced by heavy rains water runoffs from the high hills to the coastal plains. The severity of flood or landslides risk is likely estimated in that way. They are mostly related to the topography and orographic characteristic of Puerto Rico, which are moderate elevated in the center (between 1000 and 1300 meters) down to lowlands at north and south areas. These characteristics can also determine the local, man-made influence over the hydrological and geomorphological natural patterns. Therefore, the distribution of constructed areas and green spaces, as Martinuzzi pointed out, could also define the magnitude of the risks and vulnerability levels associated with earthquakes, hurricanes, storms, flood, drought and landslides [6]. Not necessary of a lower importance, droughts and landslides represent an important meso-climate risk factors to assess vulnerability in Puerto Rico. It may be influence by human hand as both, society planning and water management from natural resources. Surface and underground waters driving the intensity of the drought, could determine the capacity of the Puerto Rico's population to manage in a sustainable way, their clean water reservoirs. The short terms drought phenomena experiences in Puerto Rico's history showed us the contrary. Our last experience with Hurricane María, a Saffir-Simpson's category 4 hurricane, showed us that this infrastructure is equally vulnerable when mayor hurricanes strike the Caribbean Islands. But, in terms of the natural influence, it is also part of these macro and meso climatic scales atmospheric forces were induce the ratio of condensation, evaporation and precipitation, causing an interesting climatic heterogeneity along the southwest part of Puerto Rico [7].

Landslides produced by heavy rains posed an additional risk in Puerto Rico. Perhaps one of the most common events when heavy rains seize our skies between May and November, each year. The landslide (derrumbes) in Puerto Rico are in turn related to topographic elements described above. The inclination of land impacted by human activities (deforestation for construction) are typical case studies for heavy rain events. Between 1990 and 2010, landslide risk is more likely correlated with human factors over the natural ones. Unsustainable development, creating that almost all urban structures extend along the alluvial and flooded areas of the country, increases the vulnerability of society and its activities, its structures, as well as its heritage. Meanwhile, the other part of the population, La Rural, has been settled for years in hillside terrains with high risk of landslides. This occurred in the southern area of Ponce, when a whole community, Mameyes, fell apart by an intense event of landslide or derrume, provoked by an intense stationary low-pressure system (vaguada), in 1985 [8].

\subsection{Volcanism and desert dust}

Volcanic ash and dust transported from the deserts of the Sahara and the United States are natural and temporary-frequency risk events, at least for the time being, in the area of Puerto Rico. The volcanic ash is associated with a temporary risk, of meso-climatic scale, by the constant activity of the Soufriere volcano, located in Monserrat or Mount Pelée in Martinique. In 1902, Mt. Pelée produced a significant eruption, devastating its capital, St. Pierre. On the other hand, the volcanic activity of Mt. Soufriere, has two peaks in a year, transporting sulfur and carbon aerosols to Puerto Rico. When the wind comes from the south and southeast, the population in that area is at a high risk of respiratory diseases. Between 2009 and 2013, the air quality in the Caribbean has been dramatically affected by the increase 
in dry air masses from the Sahara Desert. This phenomenon, in addition to being recurrent, is every year, more intense, according to the data obtained by experts in this field, in Miami and Puerto Rico [9].

\section{ARCHIVES ATTRIBUTES: THE BUILDING RESISTANCY LEVEL}

At a meso-climate scale or level, we can analyze the most immediate condition or closer look to our objects of study in a tropical climate. The archival material and the building that houses it become the micro-climatic level. As Daly and collaborators stated [10], the climate local conditions is determined by the temperature, relative humidity, dew point, wind velocity and direction parameters around the areas of the Island [11]. Temperature and relative humidity levels induced by the local atmospheric conditions has been studied and are important indicators to estimate the short, medium and long-term influence relation between the archive location and the indoor air quality and stability. Therefore, these meso and micro-climate conditions must be as stable as possible to avoid damage to the physical structure of very hygroscopic materials such as paper, under tropical conditions. The buildings construction design and the climate controls are the first indoor protection level and their resistance, will depend, to some extent, to the tropical outdoors conditions. From here, the peculiarity of have "closed-green-house style" in buildings, in a topical's micro and meso climate, will depend on the efficiency of the High Velocity Air Conditioning Systems (HVAC's). As noted by some researchers in the tropics, the stability and variability of temperature, relative humidity and dew point represents the greatest challenge for the conservation of cultural artifacts in the tropics [12], [13]. In Puerto Rico, there are a wide variety of archives in each seventytwo (72) municipalities. From that number, a large portion of archives under this study were in urban areas of the northeast part, in the metropolitan area of San Juan, Puerto Rico. The "heat-island" phenomena will also be observed as a human-made or non-natural thermal secondary effect. For that reason, we included the category of "Flood (man-made)" in our study. No similar study with this approach, was found in the Caribbean area.

\subsection{A general description of Puerto Rico's archives objects collection and the micro-climate conditions}

Puerto Rico's tangible patrimonial value is composed by a spectrum of historical and aesthetic objects, whose general support is paper or its derivatives, followed by archaeologic ceramic objects and masonry buildings with wood. From these categories, paper support values objects tend to be the more numbered and vulnerable in the tropical climate. The orographic patterns in the island of Puerto Rico are varied, even when its small size of the surface area apparent the contrary. In general, archival materials are catalogued by their historical or aesthetic nature and physically, in most cases, there is not enough space to segregate them by their support. For example, in the same deposit, we can identify a collection of important historical documents, dated from the Spanish period. Others are from the last 50 years of 20th Century. Despite of the intention of segregate them by the archivist/user operations, the preservation condition will depend on the paper composition and the air quality conditions (thermos-hygrometric). Not to mention the possibility of any bacteriological or microbial development, because, in the last 20 years in Puerto Rico, the average annual temperature is near of 31 Celcius degrees and an average relative humidity that exceeds 73 percent. These external conditions would suggest that almost all our archival material is completely dependent on the efficiency of systems such as engineering controls or ventilation equipment heating and air conditioning (HVAC) has the challenge of keeping the air clean, fresh and dry all year round in a tropical climate. This task is very difficult to 
achieve under tropical conditions and possibly represent one of the main problems of preserving archival footage in Puerto Rico. In this way, natural and human events become an important element of estimation for archivists in Puerto Rico. Next, I will present a basic guide built and adapted to the estimation of natural irrigations in the tropical climate of Puerto Rico, depending on the vulnerability of the archive material, including, the variables of localization of the file, the type of structure and distribution of spaces in each case.

\section{STUDY SITE DESCRIPTION}

\subsection{The archives}

Históric Archive - Centro de Investigaciones Históricas (HA-CIH), Río Piedras is located in Antonio S. Pedreira building at the University of Puerto Rico, Río Piedras. (182410, N: $-660259, \mathrm{~W})$. This archive was founded in 1946. Its purpose is to promote historical research by gathering documents, books and magazines about Puerto Rico and the Caribbean. It has a collection of microfilms that include documents from several countries, including Puerto Rico, the Caribbean, Spain and the United States. The Rio Piedras area is characterized by urban human made pollution and urban flood events. The Historic Archive-Fundación Luis Muñoz Marín (HA-FLMM) archive deposit is located at the second floor of the main building at the municipality of Trujillo Alto, Puerto Rico (18.38697614, N: $-66.0281229, \mathrm{~W})$. The foundation was created by law in 1986, and holds the entire house, memorabilia and personal archive collections items of the first elected Puertorrican governor, Luis Muñoz Marin. The archive consists of a bunker of 21,000 cubic feet room with more than 25,000 items. The Trujillo Alto geographic area is characterized by forest tree high density, high humidity and frequent rain episodes and heavy traffic. The Historic Archive-Abelardo Díaz Alfaro (HAADA) is located at the municipality of Caguas, Puerto Rico (18.23413266, N: -66.0365695, O) in the center of the Caguas Town. Named after a great poet, literalist, and Caguas' teacher, Abelardo Díaz Alfaro, the building consist in two concrete floors, were the first floor is mainly dedicated to the archive. Caguas location is characterized by heavy rain episodes, urban flood and high humidity due to the proximity of Sierra de Cayey Mountains. The Library- Centro para Puerto Rico, Fundación Sila M. Calderón's Library (L-FSMC) is located at Río Piedras, town (18.40102184, N: -66.05317764, W). It is a private, non-profit and non-partisan organization, founded by the ex-Governor Sila M. Calderón. The main library is located at the second floor and consist of a documental life of former governors' public service from 1973 to 2005 . This include memorabilia, awards and a special collection of special communities' project and women's empowerment rights. The Rio Piedras area is characterized by urban human made pollution and urban flood events. The Jesús T. Piñeiro's Library (JTPL) is located at the Carolina area $(18.41269437, \mathrm{~N}:-65.98405479, \mathrm{~W})$ at the Universidad del Este facilities, a private non-profit university under Ana G. Méndez Education System. The library was named after Puertorrican Jesús T. Pineiro, former and first nominated governor of Puerto Rico by United States in 1946. Carolina area is characterized by earthquake liquation (mangrove filled area), coastal flood caused by tsunami, heavy industrial air pollution influence and sea salt aerosol.

\section{METHODOLOGY, RESULTS AND DISCUSION}

\subsection{A qualitative approach (Q1)}

This study proposed the construction of a basic risk and vulnerability qualitative estimation profile for seven (7) Puerto Rican archivists view. For this, we held several meeting 
workshops with the selected archives from March 2016 through July 2018. The profile was prepared with archivist own written description of possible natural risk that could affect the archive's collection object. A qualitative approach or estimation for each risk was the scope of the first questionnaire used in the workshops. Because the workshops consisted in the development of a basic risk and vulnerability profile for each archive, we agree to consider three important elements. First, identify and analyze the natural elements as events capable of producing a risk. Second, to identify the building capacity resistance to the influences of these risks over the archival material. Third, try to build a table with all risk estimation for our last task: identify the risk and vulnerability rate, depending on the biophysical characteristics of each archive location in Puerto Rico. The rationale was fundamentally related to the correlation of these environments (macro-meso and micro) and the type of material of the most valuable important support object or heritage artifact to preserve. An adopted questionnaire with a basic risk identification guide, was proposed, using FEMAS 386-2, ISO 14001 and Jones and Boer [14]. The questionnaires were prepared, distributed and filled with written description and icons indicators of how to identify the risks around each participating archive, due to their geographic location and outdoors characteristics Then, we proposed to create a table with the results obtained in each questionnaire, using an icon and develop a possible methodology to compare a similar work done in 2013. Following [33], each archivist describes their respective building characteristics in a basic qualitative description of such. Secondly, we develop a series of questions for a deeper perception data from each 7 archivist. For this, we use a second qualitative approach data results of the first questionnaire designed using ESRI's ${ }^{\text {TM }}$ SURVEY $123^{\circledR}$ web base questionnaires, discussed in section 6.1.

\subsection{The quantitative method (Q2)}

To address the estimation of the risk-vulnerability for each archive, all qualitative data was converted to quantitative data. The answers were in the first questionnaire was merged to the analysis using the ESRI's ${ }^{\mathrm{TM}}$ SURVEY $123^{\circledR}$. The results in this second analysis were compared within the preliminary qualitative risk estimation questionnaire (Q1) and the electronic questionnaire using ESRI's ${ }^{\mathrm{TM}}$ SURVEY $123^{\circledR}$ results (Q2). Finally, the base data table of Q1 and Q2, was finally used to explode a Risk and Vulnerability Assessment using a GIS spatial analysis of their respective geographical location. Puerto Rico's Board of Planning, MIPR GIS a web product, developed with ESRI's ${ }^{\text {TM }}$ ArcView, was used for this analysis. The data obtained under questionnaire Q2 was the result of the answers given by each archivist to Q1 and completed deeper in the Q2, SURVEY 123 tool. A comparison between archivist responses between Q1 and Q2 is shown in Fig. 2. Note that the specific answer does not differ much from those given in a Q1. Doing this correlation, we estimated that Q2 deep answers will be used to explode the quantification of Risk and Vulnerability for each archive.

\subsection{Data results and discussion from questionnaire: Q1 and Q2}

Using the qualitative approach in the first basic questionnaire (Q1), archivists agree to use the following formula to estimate a quantitative number for the magnitude of the material's vulnerability in terms of the risk and frequency of natural events. This time the data will depend on the location and type of structure of each archive. A correlation between the risk and its probability and frequency, after [14] is as follows: $\mathrm{R}=\mathrm{P} \times \mathrm{F}$, where: $\mathrm{R}=\mathrm{Risk}, \mathrm{P}=$ Probability and, F= Frequency. To estimate the risk, following [33] then, the natural risk 
Table 1: Risk qualitative estimation under Q1 questionnaire.

\begin{tabular}{|l|l|l|l|}
\hline Hazard event or Risk ID. & $\begin{array}{l}\text { Probability } \\
\text { (P) }\end{array}$ & $\begin{array}{l}\text { Severity } \\
\text { (S) }\end{array}$ & $\begin{array}{l}\text { Frequency } \\
\text { (F) }\end{array}$ \\
\hline Earthquake & Low & Very high & Yearly \\
\hline Seismic activity & High & Low & Daily \\
\hline Storm & Moderate & High & Biannual \\
\hline Hurricane & High & Very high & Biannual \\
\hline Flood & High & Very high & Monthly \\
\hline Landslide & Low & Low & Biannual \\
\hline Vulcanism & Low & Moderate & Yearly \\
\hline Drought & Low & Low & Yearly \\
\hline Sahara dust (aerosols) & High & Moderate & Monthly \\
\hline
\end{tabular}

level (NRL) is estimated by the following formula: $N R L=\left(P^{*} S / F\right)$, where: $N R L=$ Natural Risk Level, $\mathrm{P}=$ Probability, $\mathrm{S}=$ Severity and, $\mathrm{F}=$ Frequency. Then, the values of NRL are calculated with the Building Resistant Level, (BRL) obtained by the quantification of the responses of Q2. According to this, we can now calculate the vulnerability level of each Archive by the following formula: $\mathrm{VL}=\mathrm{NRL} / \mathrm{BRL}$, where, $\mathrm{VL}=$ Vulnerability Level, $\mathrm{P}=$ Probability, and $\mathrm{F}=$ Frequency.

After the design of the questions, all of them were translated to questionnaire (Q2) using ESRI'TM's Survey $123^{\circledR}$, platform. The questionnaire was identified as "Collection Risk Assessment" and delivered to each archivist by email, between July 22 and July 24, 2018. Survey $123^{\circledR}$ for ArcGIS is an electronic form-centric data gathering solution that makes creating, sharing, and analyzing surveys possible in just three easy steps: (1) Question design; (2) Simple answer capture and storage through mobile application or web; (3) Analyzing data in real time in a basic score table and chart distribution. The platform is an ESRITM Geographical Information System compatible program. Our study consisted in the design of a group of questions related to the level of knowledge about the risk and vulnerability levels of seven (7) archivist collections. Archives where chosen randomly and voluntary by means of an exercise with ArchiRed, a Puertorrican archives association.

The archives selection was also based on have, at least, two different geographic locations to expand the range of outcomes. After all questionnaires were received, the results were analyzed by the program Survey 123, in basic percent distribution of the answers. The core questions were designed to explore archivist perception and the level of natural risk in the tropical island such as Puerto Rico. The physical location question was important to determine the type of risk associated to the archive's geographic area in Puerto Rico. In terms of the type and value of the item's collections, and accordingly to the responses, archivist sustained that paper $(71.43 \%)$ is the type of support and most valuable item in their collections, followed by wood (14.29\%) and canvas (14.29\%). In the other hand, most of the archivist $(71.43 \%)$ agree to have a high resistance building to preserve their collections. According to archivist perception, they agree on Earthquake, as the highest risk that can harm a collection $(85.41 \%)$, followed by a Hurricane $(71.43 \%)$.

Urban and Man-Made flood risk, despite this one is not a natural risk, but equally important are the third most important risk for the archivists to harm their collections (57.14\%). We obtain the Risk Probability (P), Severity (S), Frequency (F) and Building Resistant Level (BRL) for the estimation of the Natural Risk Level (NRL). Fig. 3 and Fig. 4. The overall results obtained by Q2 and analyzed in a datasheet, clearly demonstrate how Earthquake, Flood Urban, Storms, Hurricane are the higher treats risk for historic archives collections in Puerto Rico. 
620 Sustainable Development and Planning X

Qualitave risk estimation of natural hazards of archive location

- Choose one or more Which of the following natural risk do you consider a can harm your coll... Columna Barra

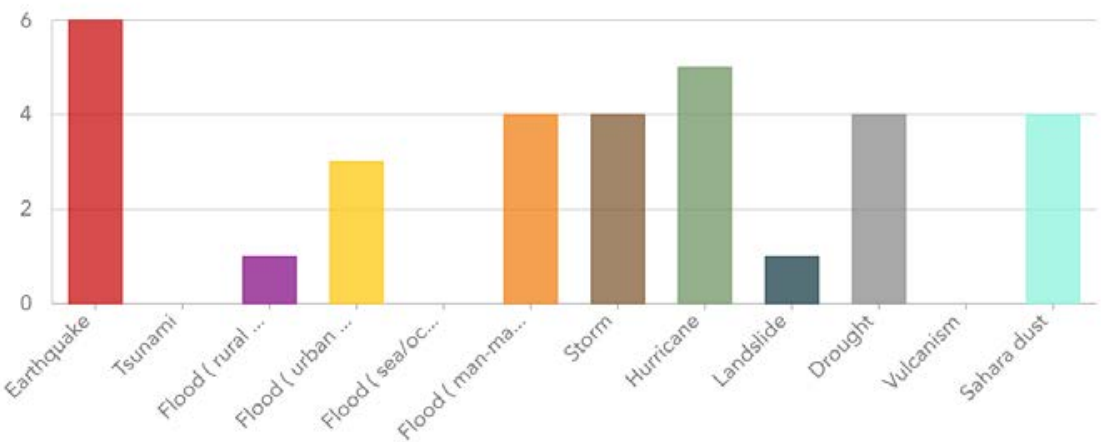

Figure 2: Natural Risk identification according to archivist perceptions.

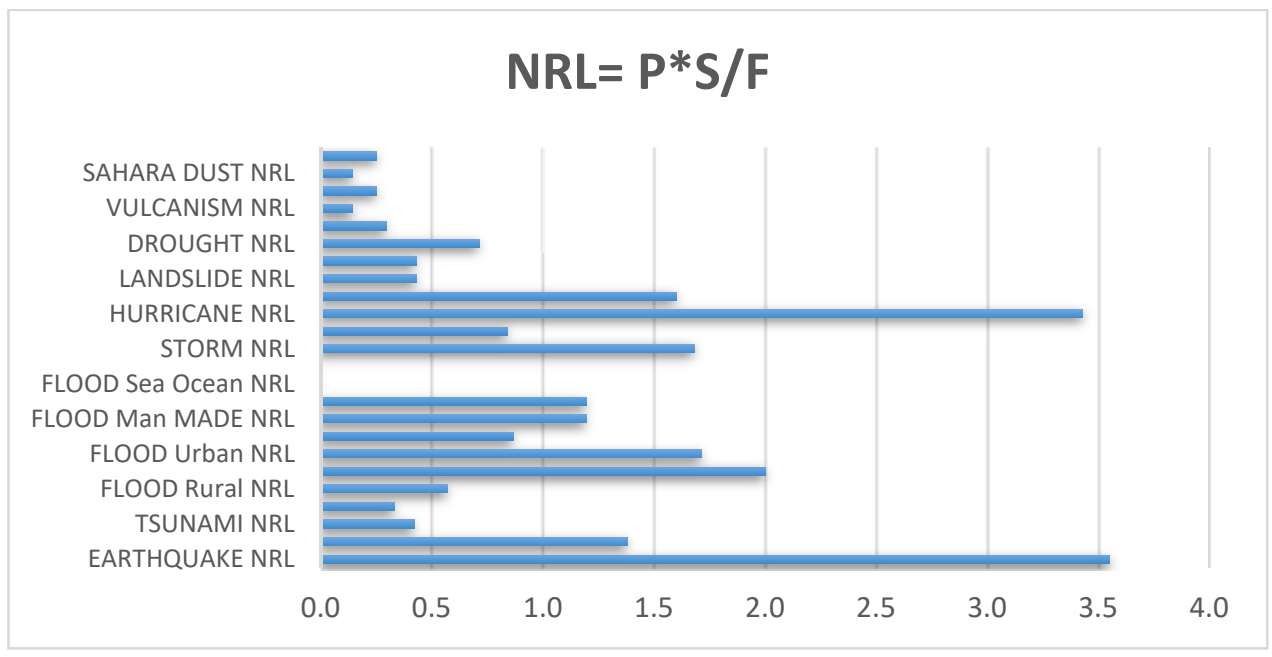

Figure 3: Summary of the NRL average calculated from the archivist responses under Q2, using SURVEY $123^{\circledR}$. 


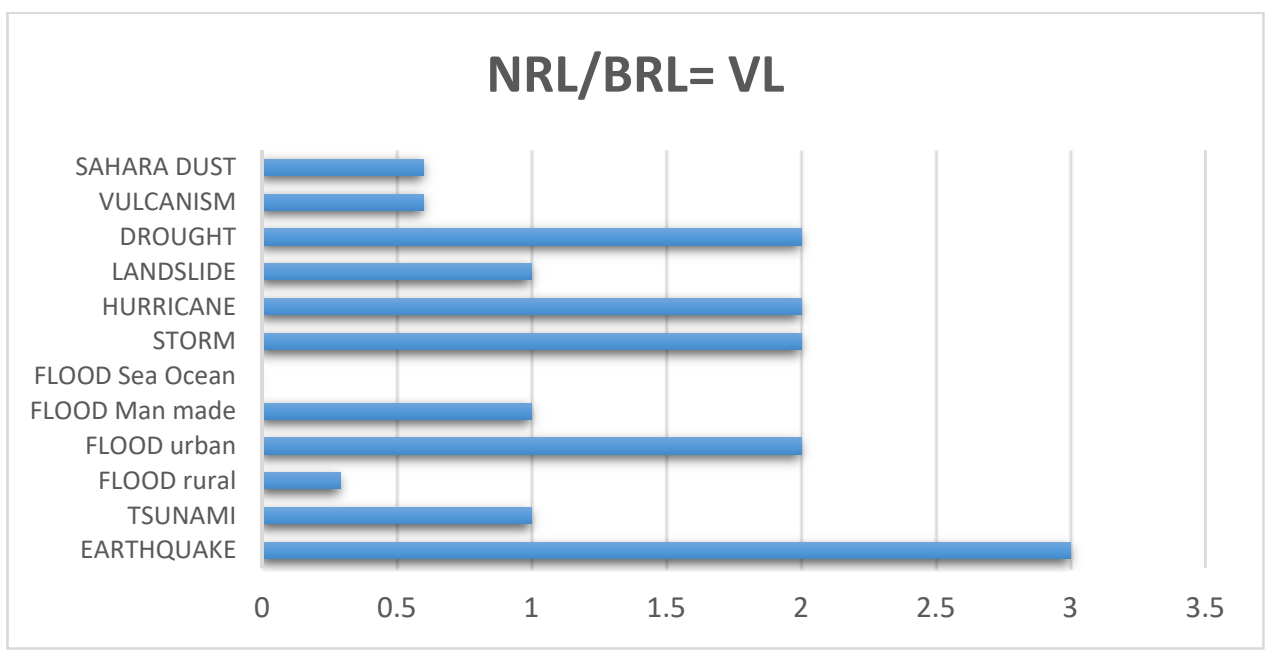

Figure 4: Summary of the VL rate (NRL/BRL) calculated from the responses under Q2, using SURVEY 123.

The perception of that drought was almost forgotten by the rest of the Puerto Rican population, except for the archivist. It is possible that the drought episode, followed by a high intense hurricane season in 2017 , could be considered as an integrated natural risk pattern in the future. The financial and environmental crisis that Puerto Rico suffers in 2018, urgently needs a sustainable master plan that integrates cultural heritage conservation and emergency and disaster planning. This study could be an initial approach in this direction.

\section{CONCLUSIONS}

After completing many trials for the estimation of natural risk in historic archives with ArchiRed association, between, June 2016 to July 2018, we finally collect some data that using Q1, as the baseline for Puerto Rico's risk and vulnerability assessment for historic archives collections. Another questionnaire (Q2) were designed, in an electronic platform from ESRI ${ }^{\mathrm{TM}}$, called Survey $123^{\circledR}$. The data collected with this tool showed a good approximation from each archivist perception by means of a simple, fast and accurate data on line. The survey includes more information that will be analyze in a future, but for now, we are focus in the estimation of several risk types (12) in the island of Puerto Rico. The results of the NRL were shown in Fig. 3 and for VL in Fig. 4. The archive name and the classification of each risk were analyzed in all questionnaires. We can first conclude that average risk level from the seven (7) historic archives in Puerto Rico, agrees on Earthquake, Hurricanes and Storm, Flood urban, as a "high" (rating =3). The others applicable average risk level by type and classification were rating as "low" (rating =1). These results had shown three main scenarios. First, could define that there is possible level of relation between the perception of harm to collections items and the level of experience risk events suffered in the past, except for Earthquake. Secondly, when we compare the average Vulnerability Level for Earthquake among the Q2 responses. Approximately, 57\% of the archivist classify their respected building as high or very high resistant ones against an earthquake. Despite the geological material beneath each archive from our list, none of the buildings were constructed 
by that time, meaning that without that experience, the perception of building resistance could be far from reality.

The average Vulnerability Level (VL) for these risks is calculated, dividing the average natural risk level (NRL) values by the average building resistant level (BRL) values. We just try to establish how the building construction type and materials characteristics could be used as a control or a control level for the estimation of vulnerability level for natural risk in Puerto Rico. As we explained before, the last earthquake that struck Puerto Rico was a 7.1 $\mathrm{M}_{\mathrm{w}}$ on the Ritcher Scale. A similar patter follows Hurricane and Storms, even urban Flood, were identified as a high risk for historic archives collections in Puerto Rico. The last hurricane that struck Puerto Rico was Hurricane María, on September 20, 2017. Classified as a Category 4 Major hurricane on the Saffir Simpsons scale, María devasted the whole island, and it is a very recent scar in archivist memory. From a long power failure period to the super slow recovery of infrastructure's features, all collection and cultural institutions in Puerto Rico had a kind of loss. Third, Drought as risk was classified identified and classified by archivist as a "low" risk $(>70 \%$; rating $=1)$. But when we ask for the level of perception concerning the vulnerable level of collections to drought risk in Puerto Rico, approximately a $86 \%$ of the archivist responses agree to classify drought as a 3 and 4 risk level, with the exception of one archivist who seems that drought is not a risk for collections. The final calculation showed that the average Vulnerable Level for all archivist was 2 or "Moderate", while the average Natural Risk Level is 1 or "Low". Accordingly, to Puerto Rico's government Natural and Environmental Resources Report of 2014-2016, [34] the last drought event suffered in Puerto Rico lasted from 2014 to 2016. The drought increased at 59\% level of the whole island and water rationing was implemented. All collections at library's and historic archives start to suffer the failure of environmental controls.

\section{ACKNOWLEDGEMENTS}

We like to acknowledge Archired Association for his contribution in this study, especially to: Yadira Tirado, José Ortíz, Elena Flores, Julio Quiróz, Maritza Ordonoñez, Iris Vera and Hilda T. Ayala. Also, we like to highlight the contribution of Rebecca De la Cruz, GIS Specialist at the Puerto Rico Planning Board in the making of the electronic survey.

\section{REFERENCES}

[1] Walker, B. \& Salt, D., Resilience Thinking: Sustaining Ecosystems and People in a Changing World, Island Press: Washington, D.C., 2006.

[2] Kasperson, J.X., \& Kates W.R., Proceeding of the National Academy of Science, pp. 7027-7038, 1983; Bankoff, G., Frerks, G. \& Hilhorst, D., (eds). Mapping Vulnerability: Disasters, Development and People, London: Earthscan Publishers, 2003.

[3] Brooks, N., Vulnerability, risk and adaptation: A conceptual framework, Tyndall Centre for Climate Change Research. University of East Anglia: Norwich, 2003.

[4] Meyerhoff, H., Geology of Puerto Rico, San Juan: University of Puerto Rico, 1933; López T. \& Villanueva, N., Atlas Ambiental de Puerto Rico, Editorial Universidad de Puerto Rico: San Juan, Puerto Rico, 2006.

[5] Wang, C., Variability of the Caribbean low-level jet and its relation to climate. Climate Dynamics, 29, pp. 411-422, 2007.

[6] Martinuzzi, S., Gould, W.A. \& Ramos González, O. M., Land development, land use, and urban sprawl in Puerto Rico: Integrating remote sensing and population census data, Landscape and Urban Planning, 79, pp. 288-297, 2007. 
[7] Jury M. \& Chiao, S., Leeside boundary layer confluence and afternoon thunderstorms over Mayaguez, Puerto Rico. American Meteorological Society, 52, pp. 439-454, 2012.

[8] El Nuevo Dia, Newspaper's front page, Oct. 8, 1985.

[9] Saharan Air Layer (SAL) image, NOAA, http://tropic.ssec.wisc.edu/realtime/salmain.php?\&prod=splitE\&time. Accessed on: 6 Jul. 2018.

[10] Prospero, J. \& Mayol Bracero, O. Understanding the transport and impact of African dust on the Caribbean Basin. American Meteorological Association, 9, pp. 1329-1337, 2013.

[11] Saiz-Jiménez, C., (ed.) Air Pollution and Cultural Heritage, Leiden: A.A. Balkema Publishers, Taylor and Francis Group: London, UK, 2004.

[12] Jamaludin N., Khamidi, M. F., Abdul Wahab, S.N. \& Klufallah M.M.A., Indoor thermal environment in tropical climate residential building, EDP Sciences, E3S Web Conference, 3(01026), pp. 1-6, 2014.

[13] MacPhaul, D. \& Etter, C., HVAC System Design for Humid Climates, Commissioning Building in Hot Humid Climates, CH2M HILL, 2003. https://www.wbdg.org/ resources/hvac-system-design-humid-climates. Accessed on 10 Mar. 2018.

[14] Jones, R. \& Boer, R. Assessing current climate risks. Chapter 4 of the Working Draft of the Adaptation Policy Framework, New York: United Nations Development Programme. Tech. Paper. http://www.undp.org/cc/pdf/APF/TP\%20final/. Accessed on: 20 Dec. 2014. 